\title{
THE POLITICAL IMAGINARY OF CARE: GENERIC VERSUS SINGULAR FUTURES
}

\section{CHRISTOPHER GROVES}

\begin{abstract}
The impacts of the activities of technological societies extend further into the future than their capacity to predict and control these impacts. Some have argued that the repercussions of this deficiency of knowledge cause fatal difficulties for both consequentialist and deontological accounts of future oriented obligations. Increasingly, international politics encompasses issues where this problem looms large: the connection between energy production and consumption and climate change provides an excellent example. As the reach of technologically-mediated social action increases, it is necessary to ask whether a political imaginary that extends itself to match this reach requires new concepts, and how far they should displace traditional political concepts of obligation, based on reciprocity and harm avoidance. This paper draws on recent scholarship on the role of concepts of care in political philosophy, bringing together phenomenological and feminist concepts of care in contributing to a positive concept of non-reciprocal intergenerational obligation that defends a constitutive connection between care and justice.
\end{abstract}

Keywords: Attachment, care ethics, Hans Jonas, intergenerational justice, responsibility, uncertainty

\section{Introduction}

The issues of how to determine what our responsibilities to future generations are, and how these relate to the tools we possess for knowing about the future, are increasingly the subject of international political debates. The emergence of a variety of transboundary environmental risks, from acid rain to ozone depletion, has led to this emerging focus, with the most obvious contemporary

Journal of International Political Theory, 7(2) 2011, 165-189

DOI: 10.3366/jipt.2011.0013

(C) Edinburgh University Press 2011

www.eupjournals.com/jipt 
condensation point for these concerns being anthropogenic climate change (ACC). Establishing international compacts to coordinate action on ACC has made only slow progress. Many have seen the best hope for producing such agreements as lying in unambiguous climatological evidence of rising temperatures and the causal role of greenhouse gases (GHGs). Nonetheless, predictions regarding future trends are hedged about with currently irresolvable uncertainties, meaning that, rather than a single future trend being identified, a set of future climate change scenarios exists.

The Stern Review, The Economics of Climate Change (published in 2006) responded to these ambiguities with a case for action that employed the methodology of neoclassical welfare economics, including integrated costbenefit analysis (hereafter CBA). The intention was to persuade political and business interests of the urgent need for action by appealing to rational selfinterest. The cost of failing to reduce GHG emissions was estimated to be between 5\% and 20\% of global GDP. By comparison, achieving a reduction of GHG atmospheric concentrations to between 500 and $550 \mathrm{ppm} \mathrm{CO}_{2}$ equivalent was assessed as costing about $1 \%$ of global GDP. The Review argued strongly that this evidence placed a strong responsibility on governments now to take committed collective action to mitigate GHG emissions and prepare for the impacts of whatever climate change is produced by the GHGs already in the atmosphere.

The problem of ACC is, like many other concerns regarding transboundary environmental risks, one which involves both complex interactions between social and natural systems, and significant temporal latency of effects. Some have pointed to the deep penetration of advanced technologies into the everyday life of contemporary societies as a major factor in the increasing number of such risks (Beck 1992). But as ACC makes clear, the technical sophistication of technologies is not itself enough to account for this increase. Technologies may be crucial ingredients in creating such problems, but what makes some dangerous and not others is whether or not their use triggers processes which penetrate deeply and widely into natural structures and systems, and whether or not these causal processes can easily be arrested or reversed by stopping or reducing the use of the technology in question.

Where causal complexity and long-term latency exist, they surround action in the present with uncertainties, undermining the reliability of scientific knowledge (Nowotny 2003; Ravetz 2004; Wynne 1992). To achieve maximal robustness, science relies on past observations to construct predictive theories about the future. But as Baer and Spash (2008: 11) point out, '[h]uman induced climate change holds the prospect of large-scale unique changes outside human historical experience'. The future, as subject to such phenomena, cannot be extrapolated from the past because there is no observation record with which the expected events can be compared. In such circumstances, there opens up 
a disconnect between the tools we employ to know the future and the means by which we intentionally and unintentionally produce it (Adam and Groves 2007). This means that, as societies depend more and more on technologies which widely and deeply affect natural systems in ways which are irreversible and/or hard to arrest, it becomes correspondingly harder to rely on scientific, past-focused forms of knowledge in order to 'read off' from predictions about the future what our obligations to future people should be (Pellizzoni 2004: $553)$.

The approach taken in the Stern Review is part of a broader approach to ACC, in which a linear relationship is assumed to exist between climate knowledge and climate action (Michel 2009: 259). Specifically, it treats the problem of how to determine the obligations of present people as one of distributive justice, encompassing questions about how to spread bads (e.g. the costs of waste and pollution) in a way which maximizes utility across generations. The Review's integrated CBA considers the best way to prevent morally significant damage (loss of utility) is to assign costs properly to expected harms, based on current extrapolations of the harmful potential of a ton of $\mathrm{CO}_{2}$ equivalent. As Baer and Spash (2008) have argued, however, there are a variety of problems with this approach. Some of these derive from how Stern treats uncertainty. Often, they argue, the approach taken confuses different categories of uncertainty, treating 'strong' uncertainty (which derives from irresolvable complexities, or ignorance) as 'weak' uncertainty which can unproblematically be assigned a quantitative weighting. Overall, Stern effectively assumes that obligations should be decided on the basis of predictions about what will happen to future levels of utility, without taking into account the kinds of uncertainties which may affect the reliability of such predictions.

Phenomena like ACC unravel the connections we have become accustomed to believing should exist between knowledge and action, with moral decisions and public policy being 'read off' from scientific evidence. As a consequence, the 'prediction-then-ethics' approach adopted by Stern is inadequate. An alternative approach would be to map out the requirements of future-oriented responsibility in contexts of deep uncertainty by examining what is logically and existentially unique about our relationship with future generations. I follow this overall approach in this paper by attempting to show that an analysis of the concept of care can help us understand the foundations of our obligations to future generations, what these might be, and how we should employ particular kinds of social practices in fulfilling them. The same general approach (without an emphasis on care) has been widely adopted by philosophers writing on intergenerational justice (IgJ) since the 1960s. Whilst being unable for reasons of space to examine this literature comprehensively, I shall argue that certain exemplar approaches within it fail to fully critique the assumptions which underlie the kind of approach taken by Stern. 
The account of care I give is developed in dialogue with the present-focused theory of obligation given by Daniel Engster (2006; 2007). Engster gives a minimalist account of care as concerned with supporting the social functioning of others. In contrast, I focus on care as a subjective orientation which is rooted in particular qualities of character, expressed through particular practices, and-most importantly-focused on particular goods. These constitutive goods are particular and singular satisfiers of needs whose own individual, singular futures are fragile and require non-reciprocal support from those to whom they matter. The reason why such goods matter to subjects is bound up with their value as the materials for projects through which subjects construct themselves as possessing identity and agency within individual and collective narratives. I agree with Engster, however, that an analysis of human subjectivity as inescapably vulnerable and dependent on others underwrites particular normatively valid obligations - only here, with respect to future people rather than to contemporaries.

My account argues that an ethics and politics of care is necessary to understand the specific position of future people vis-à-vis present ones, and that only such an ethics and politics can effectively undermine the set of constitutive presuppositions - or political imaginary (Castoriadis 1998; Buck-Morss 2000: 11-12; Taylor 2004: 28) - which supports the kind of approach taken by Stern, and which remains at least partially intact beneath the properly philosophical positions on IgJ which I examine in the next section. This imaginary represents the relationship between present and future people as a conflictual one between sovereign consumers of goods, and imagines the temporal field in which they act as facing an 'empty' or generic future (Adam and Groves 2007: 71-5), in which possibilities for action are related to key mathematical variables that describe a society as a more or less closed economic system, and where uncertainty is an additional parameter which is either to be quantified or ignored. An account of the relationship between present and future people in terms of care replaces these assumptions with ones which are more adequate to address certain key aspects of this relationship. For example, it frames dealing with uncertainty as a eudaimonistic project concerned primarily with the singular futures of constitutive goods. These goods, and the wider effects of caring for them, will contribute to how future people fulfil their needs. Central among these needs are needs for identity and agency, which, rather than being needs that must be fulfilled in addition to others, are fulfilled as part of how other needs are fulfilled. Moreover, a care perspective enables us to understand present and future subjects, not as passive consumers of goods or as isolated autonomous rational agents, but as relational, active interpreters and creators of their world. Having shown how this alternative political imaginary shapes an account of IgJ that supports intergenerational obligation, I outline some implications for the international politics of ACC. 
Philosophical Reflections on Future Oriented Responsibility

The appearance of intergenerational justice as a specific topic within applied ethics and political philosophy is first noticeable in the 1960s and 1970s, with debates being decisively influenced by both the contribution of John Rawls in A Theory of Justice (1972) and the Club of Rome's Limits to Growth report (1972). A key impact of these texts, and particularly of Limits, was the sense that ongoing commitments in developed countries to undifferentiated growth were subject to uncontrollable contingencies. What might be called the first generation of philosophical enquiry into IgJ largely concerned the role of neoclassical economics, and in particular Pareto and Kaldor-Hicks optimality criteria, in public policy affecting future generations. Many important contributions examined whether an efficient intergenerational distribution on these terms could be said to be a just one, and if not, what additional ethical principles should be used to guide choices. The resulting debates, up until the mid-1980s, also produced a great deal of sceptical reflection on the extent to which a range of traditional moral concepts were applicable in IgJ. I will pick out here for attention some key features of these debates, including characterisations of the limits of 'prediction-then-ethics' type approaches, defences of neoclassical approaches utilising CBA, and some aspects of the theories of obligation produced by Rawls, Daniel Callahan, and Brian Barry.

Douglas MacLean has referred to the neoclassical approach (which remains the basis of Stern's analysis) as the 'standard economic view' (SEV) of futureoriented obligations, pointing out that its coherence requires several basic assumptions, which rest on implicit and morally-significant value judgements. Perhaps the most basic of these is that of consumer sovereignty, i.e. that those currently with the power to dispose of earned income have the right to do as they wish with this power. Further, it is generally assumed within this paradigm that consumers are rationally self-interested, and that therefore, inter alia, they will manifest through their choices some rate of time-preference that justifies the discounting of future costs and benefits. MacLean writes:

Confronted with this fact, economists will then marshal forth other arguments about the opportunity costs of investment, improving living standards, technological progress, and the uncertainty of long-range forecasting, optimistically assuring us that the world works to make future generations at least as well off as we are, even though we explicitly refuse to regard their welfare as equal in value to our own. (1983: 189)

These 'other arguments' represent, in reality, further assumptions. The most immovable of these is perhaps that growth of outputs is inevitable, and that this growth is identical with social progress as such, insofar as growth ensures future people will enjoy more utility than present or past generations, thus ensuring intergenerational efficiency. The idea of special obligations to future generations 
is, in effect, rejected. By ensuring there are no inefficient restrictions in place on the opportunities enjoyed by individuals for maximizing utility, the future will take care of itself. Business as usual is the most morally and politically just policy.

The perspective MacLean outlines positions the subject as a self-interested, present-focused economic actor. The forms of knowledge available to such actors, informed by neoclassical interpretations of efficiency and optimality, represent the future as generic and as empty (Adam and Groves 2007: 71-2). This is the future understood as the aggregate outcome of mathematically describable, mechanistic economic processes, making society the mirror of nature. The subject, however, is within this mechanistic web, yet not entirely of it: for those who understand the laws which describe its functioning, the empty future also holds infinite possibilities for the further development of the means (such as technological innovation) to continuing economic growth. The subject who is not only self-interested but who pursues these interests rationally is one that rises above his or her non-economic entanglements, becoming a manager of resources, in control of the essential aspects of social reality (Macintyre 1981: 71). The manager's vocation is to employ disinterested economic knowledge in the service of consumer preferences. In other words, the ultimate good and value judgement that underlies the SEV is that individuals get what they want (de-Shalit 2000: 79).

The assumptions, or better (in order to emphasise their internal consistency), the imaginary underlying the SEV became increasingly influential in the 1970s on models of decision making in public policy. This perhaps reflected the prominence of public choice theory as developed by, for instance, Buchanan and Tullock (1962). Some sociologists have suggested that the employment of formal methods of risk assessment (including CBA) in the public arena 'acts as a neoliberal counterweight to bureaucratic creep and inefficiency and mitigates tendencies within government to risk aversion', thus making policy choices defensible in a society increasingly dominated by neoliberal economic and political rationality (Rothstein et al. 2006: 99).

CBA involves assigning of utility or cash values to all losses and benefits foreseen as issuing from a decision, and mandates a policy goes ahead if benefits in terms of utility are greater than costs. A defence of the philosophical foundations of CBA, specifically with respect to future-affecting choices, is given by Leonard and Zeckhauser (1986). They argue that risks associated with future-affecting choices should be treated in the same way as any other private good ('commodity'), on the assumption that exchanges of private goods between informed and competent individuals are the best way to ensure that benefits are maximized and costs minimized. The problem that public managers face in making decisions which affect the future is that market mechanisms or political processes that can generate consensus are unavailable - mainly because not all those who will be affected by these decisions can participate, whether 
in markets or in politics. Risk-cost-benefit-analysis, they suggest, can serve as a method for public officials of modelling the outcomes of different choices as if standard mechanisms of efficient distribution existed.

The foregoing has outlined how the SEV (and its extension through riskcost-benefit analysis) views 'scientific' knowledge as the best basis for ethical and political conclusions, and yet is based on a largely unacknowledged imaginary which represents the future as an empty, mathematically modellable space in which action is subject to no special obligations owed to future generations (and indeed where their well-being is assumed to be best served obliquely, via present-favouring assumptions like pure-time preference and future-discounting). Ironically, given that economists are keen (as MacLean observes) to point out how future-discounting can be justified on the basis of present uncertainties, this view nevertheless assumes that there can be no radical discontinuities between the present and future, and that for all practical purposes it makes sense to treat the future as a continuation of alreadyestablished trends. In giving now a brief survey of some key themes which emerged from philosophical reflections on IgJ in the period roughly between 1971 and 1985, I want to outline how some key philosophical contributions set out to critique the SEV and its basic assumptions. What these contributions share is a methodological approach which examines closely the logical and existential nature of our relationship with future generations-beginning from the observation that, as Robert E. Goodin notes, future generations are 'completely dependent on us for providing help or averting harm' (1985: 177). As we shall see, their success in undermining the SEV is, however, partial.

We begin with the contractarian theory presented by John Rawls. Rawls begins his treatment of intergenerational ethics with the observation that what is true of relationships between contemporaries is not true of relationships between present and future people, as these are not conditioned by Hume's 'circumstances of justice', in which taking action cooperatively to allocate scarce goods appears the most self-interestedly rational course of action. Consequently, rather than grounding an intergenerational contract on self-interested reciprocal duties, Rawls' account reflects different general criteria for rational agreement. These concern what should be included in a social contract worked out from an 'original position' where no knowledge of one's identity and final position in a particular society is available. This undermines, from the start, any moral justification for future discounting. Rawls goes further towards undercutting the economic view, proposing that basing views of justice on utility is not enough to attain 'fairness' (1972: 13). Instead, he argues for a threshold-type approach based on what he calls the 'social minimum' of resources required to establish and maintain institutions which effectively embody principles of fairness. The mechanisms required to establish this minimum must achieve 'real capital accumulation', including net investment in various forms of (effectively) technological/fixed and social/cultural capital (1972: 252). A rational actor, in 
the original position, would always choose public policy that sets a savings rate commensurable with ensuring that fair institutions are created.

Not knowing which generation one is likely to find oneself in, one should opt for the just savings policy, thus founding an intergenerational social contract on fairness alone. But, as Robert E. Goodin has noted, this appeal to fairness is still insufficient: one can expect to find oneself within some particular generation, who may or may not have benefited from past savings. But why would one then, on the basis of self-interest, take on the obligation of saving for the future (1985: 171)? Rawls assumes that the subject confronting the original position is a 'liberal' one, whose concern for intergenerational fairness is founded on the connection between self-interest and fairness. Yet such a subject would lack any motivation for such concern, as self-interest alone does not imply any demand to care beyond the present generation.

An alternative approach to the founding of an intergenerational contract, and with it, a foundation for moral obligations that would undermine the SEV, is provided by Daniel Callahan (1971), who argues that the basis of futureoriented obligation lies in a different form of subjectivity to that invoked by the economic view and by Rawls, namely the subject as parent. Here, the moral subject is assigned a particular role-based identity, one for whom problems of future uncertainty do not have the same weight as for the SEV's managerial subject, as a lack of full knowledge of what a child may need in the future is no excuse for ignoring or not adequately fulfilling one's obligations to it. Consequently, as future people are causally dependent on present people, there exists an implicit contract between those alive now and their descendants, which imposes general and particular obligations upon the present. But the idea that parental responsibility establishes such a 'contract' is criticised by Goodin. He notes that this argument has a considerable historical pedigree, but that historical examples of it also tend to recognize the dependence and vulnerability of the child as the root of obligation, rather than some implicit voluntary agreement (1985: 80-82). The existence of the asymmetry of power between child and parent is natural, but how it is acknowledged and responded to, he argues, is socially variable. It is the dependence of the child which creates parental responsibility, not some implicit idea of a contract. But the responsibility for dealing with needs can be socially distributed in many different ways.

Brian Barry's (1983) objections to 'prediction-then-ethics' approaches are more direct than Callahan's, ruling out at the start any approach that seeks to deduce the nature of future-oriented obligations from predictive knowledge concerned with costs and benefits: predicting future utility is impossible. His argument is, again, that the nature of our relationship with future generations can shed light on our obligations to them. A significant proportion of the first generation IgJ debates concerned what would be best for future individuals, exploring person-affecting rules for allocation that fell foul of what Derek Parfit (1986) famously articulated as the 'non-identity problem', namely that the power 
of present generations over the future lies in their power to effectively change who gets born and when, thus rendering logically incoherent decision rules that concern themselves with what happens to individual people. Barry avoids this set of problems, noting that what matters, from the point of view of justice, is not what individual people get out of their opportunities, but how far future generations (whoever comprises them) have access to a range of opportunities commensurate with achieving 'welfare'. He thus follows a strategy similar to that recommended by MacLean (1983: 186-7), who argues that, while the nonidentity problem shows we do not have the power to affect the lives of future people for better or worse, we do have the power to create future worlds in which better-off or worse-off people will live.

By welfare, Barry means free access to a sufficient (i.e. fair) share of resources, that is, what he calls 'productive potential', or in other words, capital (physical/natural, financial, technological, social). Future generations should be left no worse off in terms of access to productive potential than they would have been had our depleting activities not taken place-more technology and capital needs to be produced to compensate for losses.

But the problem with this approach-like the SEV-is that it demands managerial foresight. We need to at least replace the productive potential we deplete, substituting technological and social capital for natural where necessary, but to do this on a large scale presupposes a governance architecture robust enough either to manage investment directly or to ensure that market mechanisms exist to direct resources towards replacing lost capital. Treating the capacities needed by future people as productive capital would be a necessary conceptual step, but, as various critics of neoliberalism have pointed out, this effectively extends market relations and the forms of evaluation they require to cover both non-market social relations (Fine 2003) and the support provided by ecosystems (O'Connor 1994). A variety of commentators have written extensively on the difficulties with such an approach. These include epistemological problems entailed by extending market relations to assign values to natural systems (Farrell 2010), and issues of injustice arising from, on the one hand, the forcible translation of incommensurable values into commensurable forms (Baer and Spash 2008: 20-21; O'Neill 1993: 119-21; Raz 1986: 350-51), and on the other, the deepening of inequalities of accumulation associated with such strategies (Harvey 2003; O'Connor 1994). As well as creating new ethical and political problems, the approach recommended by Barry does not address the epistemological issues implied by the SEV: although we do not face the problem of predicting utilities (as in the SEV and Stern Review) we are required, as Barry acknowledges, to base our decisions now on predictions about the efficiency of our efforts to compensate future people with more capital (Barry 1983: 27-9). But the power of the present over the conditions of life of the future comes with an uncertain degree of ignorance. This places in question our confidence that we can adequately assess how to proceed on the basis of the kind 
of comprehensive CBA that Leonard and Zweckhauser recommend as a major input into policy. It is just this kind of policy input, however, that is required if the distributivist scheme Barry calls for is to be put into practice.

These three positions represent key examples from the philosophical literature to derive general future-regarding obligations from reflections on the nature of the relationship between present and future generations. Each is, however, insufficient. Barry's approach recognizes most explicitly the problems with the SEV, but fails to extricate itself from the imaginary which underlies it. Focusing on productive capital does not avoid the disconnect between knowledge and action which bedevils utility-based approaches. Rawls fails to justify futureregarding obligations based on the rational self-interest of the 'disinterested' individual subject. Callahan attempts to justify the existence of a social contract with future generations, and with it, the existence of welfare rights for future people, by drawing an analogy with the situation of parents. But this analogy, as Goodin points out, is based on a false premise regarding the contractual basis of parental responsibility.

\section{Care, Subjectivity and Future-Orientation}

In this section, we examine in detail how a care-based approach can deal with the disconnect between knowledge and action that bedevils conventional understandings of future-oriented responsibility. This will not only enable us to justify a general obligation on the present to act in the interests of future people, it will offer insights into what concrete expression this obligation might take (what kinds of specific duties follow), and how these concrete duties need to be fulfilled (i.e. what kinds of attitudes and practices need to be employed in caring). The account of care I give here identifies caring in relation to particular kinds of constitutive goods, which serve as the materials for projects through which subjects position themselves as possessing identity and agency within individual and collective narratives.

It has been noted that attempting to ground IgJ on an account of the rights of future generations against those of present generations is insufficient to fully articulate common intuitions about what present people owe to their succesors (Meyer 2005). A care-based account can provide a more comprehensive account of future-oriented obligation, one which unites both normative justification and motivation. It does so without returning us to the kind of 'prediction-thenethics' approach exemplified by the SEV. In what follows, I develop such an account by extending an intergenerational interpretation of care ethics I have outlined elsewhere (Groves 2009) in dialogue with the work of Daniel Engster (2006; 2007), acknowledging also the contributions of others such as Joan Tronto (1993) and Fiona Robinson (1999) on how care ethics needs to combine both care and justice. Although feminist writers have contributed most to our 
understanding of what is ethically significant about caring, I want to defend a concept of care here rooted in phenomenological interpretations of the concept, as given by van Hooft (1995), for example. This is because, if we want to define what caring is, we need to understand what it aims at, that is, what kinds of goods it is concerned with. To understand the meaning of these goods, it is necessary to appreciate phenomenologically how they help the subject organise the boundaries of experience represented by a contingent, uncertain future. I will therefore outline what is distinctive about care with the assistance of the concept of a singular future. Its orientation towards singular futures separates the subject-of-care decisively from the subject as it is represented within the economic-managerial imaginary of the SEV, oriented towards a future which is empty and generic.

I begin by contrasting my concept of care sharply with that given by Daniel Engster. Care, for Engster, is

everything we do directly to help individuals meet their vital biological needs, develop or maintain their basic capabilities, and avoid or alleviate unnecessary or unwanted pain or suffering, so that they can survive, develop and function in society. (2007: 28-9)

Engster also stipulates that such activities require certain attitudes or virtues, and must therefore be done 'in an attentive, responsive and respectful manner' (31). In this way, he attempts to avoid the conceptual overstretch exemplified by Joan Tronto's definition of care as 'everything we do to maintain, continue and repair our "world" so that we can live in it as well as possible' (1993: 103). In addition, how care is performed is important, and whether someone is actually cared for or not as a result of what is done matters.

What Engster's definition does not include, however, is mention of what specific kind of goods are aimed at by caring virtues and activities. Here I agree with Gheaus (2010) that it omits consideration of important needs which, I shall argue, relate to the constitution of identity and thereby to constitutive goods. In particular, these have to do with how experiences of attachment serve to produce and sustain the identity of the individual and her sense of having individual and (with others) collective agency, 'living forward' into the future. As a result, Engster's definition does not fully escape from the imaginary that underlies the SEV. The subject of care, as Engster represents it, is first dependent, then care-giving. Looked at from a developmental perspective, it receives the care needed to develop the basic capacities necessary for social functioning, then on assuming the role of carer, cares in turn for others who are in a position of dependency.

In childhood and old age, and at many points in between (as when we are ill or subject to other contingencies), we are dependent on others, meaning that relationships between people tend to be asymmetrical rather than reciprocal. Indeed, Engster notes that dependency is an inextricable part of our everyday 
lives even when healthy or otherwise capable, as we depend on a complex web of caring services provided by others, and by others for others, in order to survive (Engster 2007: 41-3). True as these observations are, as Engster represents the subject, its dependence remains essentially a relationship whose nature can be understood by isolating those involved in it as producer and consumer of a good. As dependent, the subject is simply characterised by a lack which subjects her to dependence on the efforts of another. This, however, misrepresents the relational nature of care, producing an individualistic picture of subjects whose relationship with others, while asymmetrical, is asymmetrical in one direction only.

If we examine the nature of care in a phenomenological and developmental context, we get a more complex picture of dependency. Psychologists working against the background of attachment theory, such as Daniel Stern (1985), have noted how closely attachment, and the development of a stable and resilient sense of self, is bound up with the manner in which needs are satisfied. This is because experiences of attachment, from infancy onward, produce a sense of what can be relied on, and with it, expectations of the future. Attachment is the medium within which children construct, in concert with significant others, a sense of an uncertain future that nonetheless offers the promise of the continuation and development of our selves. Furthermore, attachment relationships are more dialectical than Engster's capability-based account allows. Stern, BruschweilerStern and Freeland (1998) describe the mutual dependence between mother and child, which is a product of the mother's non-reciprocal attentiveness to and effective caring for her child. Even though the growing child does not consciously 'take care' of the mother, its own attentiveness to her has, phenomenologically, to be seen as two sided. Not only is it bound up with the child's need to ensure that its own needs are met, but it also involves responding attentively to the moods of the mother.

It is through these responses that the child awakens affectively to the intrinsic identity of her caregiver. The narrative in which mother and child are involved is not one of production and consumption (even if what is being produced and consumed is caring activity), but one of ongoing, developing mutual attachment through which their respective identities are transformed. Although it is easy to identify here a non-reciprocal and asymmetrical relationship of caring directed from mother to child, neither partner is simply a consumer of care. ${ }^{1}$ To characterise their relationship as simply one-way dependent at different moments (at $t=1$ the mother cares for the child; at $t=2$ the child, now grown, cares for the now elderly mother) is inaccurate. These are important observations, as we have now moved away from Engster's minimal understanding of care. Although there are more minimal forms of care that are not necessarily bound up with emotional attachment, these are themselves derivative upon, developmentally speaking, the more involved sense of care I have outlined here. Care, in this fuller sense, is bound up with attachment, and as 
such is directed towards particular kinds of values. These values are constitutive in nature. They are others on whose intrinsic well-being we are dependent to some degree for our own.

These values can be contrasted with goods that are of purely instrumental value, i.e. purely useful relative to the subject's interests, with any functionally equivalent satisfier being substitutable for them. Constitutive goods, on the other hand, have value as ingredients in a meaningful or good life. Their worth stems from their existence as particular individuals. Their value to the subject lies in how their intrinsic worth adds to the subject's own flourishing. I have noted already how attachment relationships create stable expectations, with which comes the possibility of trust (in other humans and in the surrounding world in a more general sense). Looked at as constitutive values, objects of attachment can be seen as shaping an emotional armature in which the subject's life can take on a narrative structure. In attachment psychology, a similar idea is expressed in the concept of the 'safe space', in which the infant learns to explore the world around it, cognitively modelling in the process the responses and, later, the interests of the other subjects whose comings and goings define this space (Bretherton 1992). The emotional space defined by attachments is one populated by others who have their own pasts and, importantly, their own dependent, singular futures.

The first attachment relationships, developmentally speaking, are with caregivers who are attachment objects. But, as I have already noted, there can be care relationships without attachment (although these are derivative upon the more constitutive kinds of care described above). Conversely, care tends to define our non-reciprocal relationship with other kinds of constitutive values on which our capacity for identity, trust and agency is dependent. Developmentally, various different classes of attachment objects extend and consolidate the 'safe space' of reliable relationships, generating in the process a variety of forms of trust and supporting a secure sense of identity. I have proposed (Groves 2009), following Marris (1996), that there are a number of classes of attachment object which play this identity-constitutive role. These include other particular people, but also places (Altman and Low 1992; Morgan 2010), cultural objects (Wallendorf and Arnould 1988; Young 1989), institutions (Edelstein 2004) and ideals (Marris 1996). All these kinds of objects can be enlisted as ingredients for the subject's sense of individual identity and group belonging, creating webs of attachments which consolidate secure patterns of bodily and affective engagement with the surrounding world, one's sense of self, and confidence in one's own agency. Clearly, the relationship between the subject and its attachments is not generally parental in nature, yet the subject's concern with a landscape, an institution or an ideal identifies the object in each case as being of constitutive value, as sui generis, and as essentially irreplaceable-such that the loss of the object does not simply call for replacement, but may also (to a lesser or greater extent) solicit a response of grieving (Marris 1986: 1). 
Attachment, in this sense, is not another need over and above others. Rather, attachment to constitutive values is an additional dimension of how other needs are satisfied over time. Fraser (1998) has argued that needs must, in order to be adequately understood, comprehended in their historically evolving forms. We do not encounter 'general' or 'basic' needs, except in cases of extreme distress (when, on a purely instrumental basis, any roughly functionally equivalent signifier will suffice). Instead, on surveying how needs are met in a given culture, we encounter particular and singular objects that have come to count, within specific socio-cultural contexts, as satisfiers. To understand what is required to supply a subject's needs, it is not enough to posit a general or basic need and then select an instrumentally useful satisfier. Neither is it sufficient to posit an objective list of needs and then score someone's flourishing on how far they have satisfied these needs. This fails to appreciate 'the role of history and narrative in appraising how well a person's life goes' (O’Neill et al. 2008: 196), and how far a particular subject's life is provided with a range of singular constitutive goods through which she is able to construct, on her own and with others, her own projects, sui generis commitments that define 'what her life is about' and contribute to her sense of integrity, her capacity to be a future-affecting agent (Smart and Williams 1973: 116-17). As ingredients in these projects, constitutive values bring with them their singular futures (which are themselves dependent on contingencies that are to some extent, outside direct control). The singular futures of these values therefore matter intrinsically to the subject, as what happens in these futures affects the flourishing of the subject that cares about them. It is because of their intrinsic value that the subject needs to cultivate certain virtues in order to care properly. To care properly is, for example, to care respectfully: what we want to do for $x$, whether $x$ is another person, a painting, a feature of a valued place, or an ideal may not necessarily be what is best for $x$ 's future. Learning attentiveness, patience and respect is a vital part of learning how to care, not only in our most intimate relationships, but in extended forms of care-both in caring relationships where little or no attachment is involved, and in attachment relationships with non-human others. The kind of non-reciprocal care which is involved in early attachment experiences, directed at modelling, anticipating and tending for the needs of particular or singular others, thus helps develop the kind of care which we exercise with respect to a variety of significant objects.

Subjects, as subjects of care, are not therefore simply consumers. Instead, they are existentially dependent on a variety of constitutive values which, whilst they may have some instrumental value, primarily embody forms of life, the ways in which needs are satisfied for particular people within specific cultures, who participate in these forms of life through their projective care for constitutive values. Though Engster is right to recognize that human life cannot be adequately understood without acknowledging the place of dependency within it, he does not go far enough in detailing what this dependency entails. 
Human agency is developed, in the first place, through attachment, which supports reliable expectations and a secure sense of a hospitable future. But agency is therefore inseparable from care, from a need to pay respectful and responsive attention (employing imagination and empathy) to the needs of the constitutive values upon which our capacity for making sense of our place in the world depends. Care, which connects together self-concern and concern for others, entails concern for the flourishing of constitutive values, for their singular futures.

\section{From Attachment to Intergenerational Justice}

The account of care I have given so far defines it as emerging from the attachments which grant to the subject a sense of 'ontological security' in the world it inhabits. However, if care is primarily oriented towards the singular futures of attachment objects, how is it possible to make a connection with spheres of concern which extend beyond the boundary of our own lifespans? I will now show how a care perspective can help us understand how care necessarily extends beyond our perhaps parochial circle of attachments in the present, and further, towards future people as such. I will also show how the necessary extension of care underwrites a normative justification of the obligation to care for future people, without which the strictly moral content of a care perspective remains in question.

Thus far, the account of care I have given may be interpreted as what Habermas (1998: 13-14) refers to as an 'empiricist' ethics. I have told a developmental story which relates to the genesis of care for constitutive values, and to how this capacity for caring extends itself to encompass different varieties of attachment object that, over time, play a role in shaping the identity and agentive capacities of human subjects. As I noted earlier, the role of 'modelling' (a concept drawn from attachment psychology) in the development of care is central. Employing imaginative perspective-taking to try and anticipate the actions and needs of others is a capacity that is trained by modelling, firstly, the reactions and dispositions of caregivers, and then the interests and singular futures of an expanding range of others. The next logical step in presenting an account of care as a moral orientation might be to show how modelling, a part of individual psychological development, becomes generalised more widely to cover less proximate concrete others and distant hypothetical others. Consequently, it extends to explore what count as the wider conditions of wellbeing for those constitutive values closest to us, before going on to (more sketchily) model the needs of distant individuals, by drawing on familiar experiences to attempt to model the unfamiliar (Groves 2009). Further, we come to recognize that our acts of caring, and our being-cared-for, are themselves both dependent on the acts of others, and on bodies of practice and institutional 
arrangements, which provide the support systems that make our own extension of caring possible (Kittay et al. 2005). We might also add that they are dependent on extra-social, i.e. ecological relationships.

True though these observations regarding the need to practice extended care may be, none of this supplies the normativity that, for Habermas, elevates a merely empirical, genealogical account of morality to a moral theory as such, one which 'accounts for the normative priority of duties', employing criteria such as justice or fairness. So far, we remain tied to particular obligations that attach only to a particular individual on the basis of what she happens to care about. I shall now show how the structure of care enables us to derive normative content from the account I have given, building on an argument presented by Engster. Following Alan Gewirth, he argues that we should analyse the "moral claims and principles necessarily implied by people's actions' (Engster 2007: 45 ) in order to understand what obligations follow immanently from the role care plays in human lives. Given that all humans are subject to external and internal contingency and uncertainty they are thus adventitiously dependent on webs and circles of particular people and particular institutions. These people and institutions provide them with the support they need in order to meet their basic needs and to exercise agency in the face of uncertainty. Consequently, Engster argues, individuals have a duty to act in accordance with the principle that it is right to recognise the claims of others to care as morally valid, subject to certain conditions, that is, without 'significant danger to ourselves, seriously compromising our long-term functioning, or undermining our ability to care for others' (49). If someone fails to acknowledge this duty, then they enact a performative contradiction by implicitly renouncing the principle which has justified and will continue to justify their own entitlement to care.

Can we adapt Engster's argument to justify extending care, via the modelling of what instrumental and constitutive goods (including institutions and social relationships) their flourishing may require, to future people? In some ways, it is even more emphatically relevant here than it is to relations between contemporaries. Present people have benefited from the care of previous generations in a variety of ways. Not only have they benefited materially from technological and economic capital, and the evolving relationships between society and nature, that have resulted from the historical processes that shape the present, they have benefited from the care of previous generations for thick webs of attachment objects. ${ }^{2}$ Their care has shaped a repertoire of particular and singular satisfiers which conditions the cultural 'space of possibilities' in which individuals will develop their own attachments. Through their own individual attachments, individuals thus participate in collective narratives that help consolidate stable expectations of the future, shaped ultimately by ideals of the good life. It would therefore be contradictory, as in Engster's account of relationships of care between contemporaries, for present people to ignore the obligation to extend care towards the future, as to do so would imply that 
they have disavowed a principle on which they, as beneficiaries of past practices of caring, have relied. But more fundamentally, my analysis here has shown how care is, at bottom, care for the singular futures of objects of attachment. Although these singular futures can of course be of varying extent (ranging, for example, from the lifespan of my children to the future of a landscape in which nature and human society will continue to be intermeshed), they tend to link both proximate and distant generations. This is significant insofar as the logic of the relationship between the subject of care and its objects of attachment means that the ultimate significance of an individual's life rests on what happens beyond its end (O'Neill 1993). This is true both from the point of view of the individual living now anticipating how the future will turn out, and will be true for posterity, looking back on what she did. Disavowal of care for the future as such implicity entails a disavowal of care for the constitutive values about which we do actually care, here and now. As such, it denies the constitutive role of aspects of human subjectivity which are fundamental to the meaningfulness of human experience, and to the possibility of human flourishing as such.

The role played by care in human development thus enables us to derive a normative justification for extending caring practices towards a future extending beyond our own life span. We can now go on to say more about what concrete kinds of responsibilities extended care, in the present and for the future, entails. As I have noted, one's care is, developmentally speaking, initially directed at the needs of attachment objects: identifying what they may require (instrumentally and constitutively speaking) in order to flourish as the kinds of entities they are. As suggested earlier in this section, this will necessarily enlarge the sphere of care over time. My care for a friend involves me in, to some extent, care for her attachment objects, insofar as they are constitutive of her flourishing. But it also demands that I, where necessary, engage in reflection and action to help build the kinds of social relationships (and, we might add, the kinds of relationships between the society we are members of and the non-human world) that are most conducive to the flourishing of the constitutive others we care about (Groves 2009; Kittay et al. 2005). When it comes to people for whom we care, opportunities for work, welfare provision, access to education, and healthcare, childcare and long-term care for the elderly and disabled are all matters which will arise, sooner or later, for the individual who develops as a subject of care. But this is not just about dependency in the sense of consumption of services. As noted in the previous section, care entails respect for the intrinsic capacities of others. It requires that we build relationships which support the caring of others. Care thus takes us far beyond face-to-face attentiveness: it aims at building and sustaining relationships of solidarity that support strategies of mutual reliance in the face of an intrinsically uncertain future (Marris 1996), and which respect the non-instrumental value of a range of others (Jaeggi 2001). Caring for future generations implies further acts of imaginative perspective-taking, in which virtues additional to those of respect 
and attentiveness are required. Respect becomes humility in the face of one's dependence on contingency. This dependence means one must recognise that one's capacity to influence the future is limited, and tempered by the agency of known and unknown others. Attentiveness implies focusing on what will best promote the resilience of future people, in the face of as yet unknown challenges both to how they obtain instrumental goods, and to how far they will be able to engage with the constitutive goods which the present passes on to them.

Caring for the future also implies striving to be critical of the past. As well as constitutive and instrumental goods, the narratives into which we are placed contain antagonisms too, deriving from failures of care and of justice. Part of the meaning of care, however, is that it should actually achieve its goals, that is, should actually help provide for the needs of others. Employing sympathy, perspective-taking and imagination to attend to these needs requires that all means of satisfying needs, and the forms of attachment they support, need to be assessed for their adequacy. Some attachments may, for example, be negative for the flourishing of an individual rather than positive. The repertoires of satisfiers that historical narratives provide as sources of attachment are not simply to be accepted, as if one's identity were simply imposed. We discover ourselves to be inserted into traditions, stories we did not initiate, but 'when a tradition is in good order it is always partially constituted by an argument about the goods the pursuit of which gives to that tradition its particular point and purpose' (Macintyre 1981: 206). The capacity to care for objects of attachment, as anchors for the projects which shape one's life and how one participates in wider narratives, arguably constitutes the core of what Macintyre calls the 'relevant virtues' (i.e. subjective orientations) without which traditions simply decline and die. Caring means constantly trying to understand how adequate are current arrangements to satisfying an other's needs. Because caring always takes place within a narrative that supports identity and belonging, it inevitably involves articulating a thick concept of the good life rather than (as Engster maintains) a minimal conception of needs and their fulfilment. Any critique of how needs are currently satisfied cannot therefore be undertaken in relation to a fully objective criterion. Instead, it can only be performed through dialogue between different understandings of flourishing that aim to determine what different collections of singular and particular satisfiers reveal about the nature of needs in general. While predictive knowledge of the kind the managerial imaginary relies on no doubt has its place in the kinds of deliberation which care requires, it does not occupy a primary position. Efficiency becomes one value to be weighed against others.

I have argued in this section that such an obligation can be rationally defended as a way of making sense of the commitments that are implicit in the dialectical relationship of self and other expressed in caring. I have also suggested we need more than this to make this obligation effective, or to understand what is concretely implied by it. What makes the obligation compelling and motivates 
complying with it is the emotional and practical content provided by caring, and the extension of a web of connections in the present to form networks of solidarity that reach out towards the future. The positive goal of care is not to pass on a set of consumable goods on which future generations will be passively dependent, but to pass on the 'materials of care'. These materials include the narratives which are part and parcel of how material goods are organised and interrelated as particular and singular satisfiers. Part of the labour of "passing on' is understanding what forms of material needs-satisfaction will provide the most resilient armature for supporting these narratives. What is passed on is, at bottom, the capacity to actively relate to objects of attachment and to care for them. In other words, the ultimate object of care is care itself, as embodied in the existence of particular individuals who define themselves within specific individual and collective narratives. The continuation of the capacity to care, and to flourish through caring, will protect what Hans Jonas calls the 'existence and essence' of humanity from destruction. Yet it is ultimately only through the singular futures of what we care about that the future becomes a concrete object of obligation for us.

\section{Conclusion: Caring for the Future and the Politics of ACC}

I return now to the problem with which we began, and the relevance of my care-based approach to how international politics addresses ACC. Thanks to the long-term latency of its consequences, ACC cannot be entirely stopped simply through instigating a stringent programme of GHG emissions cuts today. Adaptation measures for those most directly exposed to its consequences will also be necessary. As discussed earlier, the Stern Review represents perhaps the most comprehensive attempt to present an argument for extensive mitigation and adaptation measures now. However, as a contemporary example of MacLean's SEV, the neoliberal economic and political rationality according to which the Review formulates this argument directly supports a particular, and questionable, understanding of how to take responsibility for uncertain future consequences of present actions. As an example of an SEV-based 'prediction-then-ethics' approach, the Review's CBA analysis frames the options for rational action in a way which treats arguably irreducible uncertainties in a reductive way (Baer and Spash 2008), and depicts legislators and businesses alone as having the managerial agency and expertise needed to deal effectively with these uncertainties. In closing, I want to offer some suggestions why, given the account of care-based responsibility given above, this approach represents an inadequate framing of the future-oriented obligations entailed by ACC, particularly when compared with other ways of thinking about these obligations (such as the Greenhouse Development Rights approach). I will also suggest, however, that even these alternatives require significant adjustment in order to effectively embody a care-based perspective. Building solidarity in the face of uncertainty is 
perhaps the most significant ethical and political task imposed on us by ACC. This, however, requires the promotion and sustenance of other forms of political agency than that of an idealised neoliberal manager, which are oriented towards care for singular futures.

The CBA undertaken in the Review sets out a case for action based on an optimal level of emissions reduction, i.e. one that will not entail excessive global GDP cost, and which will therefore be more likely to command wide agreement. But the losses represented here are consumption costs, seen from the perspective of the present against a future discount rate. In a world subject to environmental and social disruption caused by ACC, the erosion of capabilities, cultural stability and capacity for stable attachment are dimensions of loss which will arguably increasingly emerge as the focus for grassroots efforts to shape international political debates. The singular futures of cultures and the infrastructures of attachment which support them are inseparable from how concerns for instrumental needs may be addressed, as is already evident in the campaigns waged by Pacific island states and indigenous peoples from other regions threatened by ACC (Blomme 2010). Seen in terms of losses of incommensurable goods, which cannot be captured within the terms of the SEV, the effects of present actions on future people require a different normative framing of obligations.

To address these issues successfully in political agreements designed to coordinate international action, it is vital to build in explicit recognition of the unequal (and increasing) impacts of ACC across space and time, of the ways in which these impacts may include irreversible losses affecting the 'materials of care', and of how these future impacts relate to existing global inequalities-including inequalities in the degree of responsibility for ACC, given historical patterns of emissions production. An example of an approach which suitably provides a concrete set of proposals for differential national allocation of responsibilities, together with a normative, global social justicebased justification for action is the Greenhouse Development Rights (GDR) framework (Baer et al. 2008). The GDR approach aims to address distributive conflicts over the allocation of emissions reduction targets in ways which respect historical global inequalities in social development of human capabilities. It assigns rights to emit GHGs to countries based on how far their populations fall short of an agreed development threshold. As a way of establishing new rights in international law, GDR recognizes the transboundary and intergenerational solidarity required by the expansive logic of care, along with the asymmetries of power that are part and parcel of caring relationships (Robinson 1999).

The GDR approach commends a variety of management tools for the implementation of these rights. As such, it reflects a tradition of thinking about adaptive international governance which, for some, is exemplified by measures such as the Montréal Protocol on reducing the use of ozone depleting chemicals (Mascarelli 2010). Adaptive governance may employ a variety of approaches at 
a variety of levels (sub-national, national, regional, global) to reduce emissions and enhance adaptation, and will emphasize the need for reflexive and iterative policy formation. ${ }^{3}$ Yet this form of governance is not sufficient to fully embody a care-based perspective.

The learning process under adaptive governance requires wide stakeholder participation, both to aid policy formulation and establish its legitimacy (Michel 2009: 262). Yet this view of governance focuses primarily on the needs of policy makers. It might aim to elicit information from particular stakeholders and/or the public at large - in particular, what matters to them and what may be threatened by ACC in particular places. It might also aim to increase participation, in some sense, in the policy process. But it needs to go beyond both these measures in order to be effective, because to be effective it needs to treat all those affected by ACC as active participants in their own futures, and the shorter- and longerterm futures of those things they care about. Flourishing is tied to identity and agency, which are enhanced or degraded by how far, and in what ways, a set of diverse yet interdependent needs are met. Whether care is practised well or not depends largely on how far this connection is recognized, and how far the care of individuals for what matters to them is supported. As argued earlier, care implies asymmetrical relationships between carers and cared-for, but these relationships are multiple. It is not enough to treat individuals as consumers, even of care: those who receive our care are carers too.

To be genuinely adaptive, responses to ACC need to be shaped by the active capacity of those affected by it to express their care for what matters to them, and for what will matter to those who succeed them. The proper role of those with power is thus, in partnership with the relatively powerless (Robinson 1999), to promote and support their capacity to do this. As noted above, contemporary campaigns for the international recognition of the irreversible future impacts of ACC have often focused on the multi-dimensional and interconnected effects of environmental and social disruption on capacity of human beings to continue to actively care for themselves and for what matters to them. The stories these campaigns tell about the future differ from those offered by policy discourses, themselves considered as a special class of narrative. In relation to ACC, policy narratives tend to focus on the global dimension of political coordination, and to represent politicians, policy managers and, sometimes, NGOs as the active participants in this drama. In order to promote and support the agency of those affected by ACC, it is necessary for people to be able to tell their own stories of the future in order to enhance how to live gracefully and continue to flourish amidst uncertainty. The 'serious, and perhaps uncomfortable, questions about who we are and what we want to be' (Gardiner 2006: 402) that will necessarily accompany adaptation can only be answered, initially, from the localities where particular disruptions will be felt, producing narratives which draw on a storehouse of attachments both to enhance resilience, and to articulate demands for care from others who may be able to assist. 
This requirement is therefore for more than consultation. It concerns a reimagining of what can be done, by those affected in particular places and at particular times by ACC, to extend their own individual and collective agency, based on their own singular attachments. Examples of such processes of reimagining have been undertaken by the environmental artists Newton and Helen Harrison, whose Greenhouse Britain (2007) represents a form of storytelling about ACC which brings together scientists, engineers, ecologists, and others who are all inhabitants of particular places in the UK, such as the Mersey Estuary and the Lea Valley, in constructing future scenarios concerning the effects of rising sea levels on these locations and the communities anchored within them. By exploiting generalisable scientific knowledge and local knowledge of connectedness, these scenarios focus on how communities may change their ways of living as they give ground to rising waters. Through dialogue and collaboration, the work re-injects human agency into a process which, in traditional policy narratives, is something which simply 'happens to' a passive populace. The goal is both to enable people to give voice to fears and offer them the opportunity to retrieve concrete hope in the face of uncertainty, through their capacity for future-oriented care.

\section{Notes}

1 It is for this reason that the perspective I develop here does not fall victim to Sarah Lucia Hoagland's (1990) critique of Nodding's concept of unidirectional caring as inevitably reinforcing static inequalities of power.

2 It should be noted, of course, that they have also inherited the legacy of previous generations' lack of care: slavery, colonialism, and of course the over-use of fossil fuels all, for example, enter into the genealogy of the present.

3 Whatever governance model is chosen to address ACC, however, problems of power in bargaining, implementation and enforcement will need to be faced (Thompson 2006). This issue lies beyond the scope of this paper, however.

\section{References}

Adam, B. and Groves, C. 2007. Future Matters: Action, Knowledge, Ethics. Leiden: Brill.

Altman, L. and Low, S. 1992. Place Attachment. New York: Plenum Press.

Baer, P. et al. 2008. 'Greenhouse Development Rights: Towards an Equitable Framework for Global Climate Policy', Cambridge Review of International Affairs 21(4): 649-69.

Baer, P. and Spash, C. L. 2008. Cost-benefit Analysis of Climate Change: Stern Revisited. CSIRO Working Paper Series 2007-2008, May.

Barry, B. 1983. 'Intergenerational Justice in Energy Policy', in D. MacLean and P. Brown (eds), Energy and the Future. Totowa, NJ: Rowman and Allanheld, 15-30. 
Beck, U. 1992. Risk Society: Towards a New Modernity. London: Sage Publications.

Blomme, W. 2010. 'Precarious Balance: Challenges to Place and Home in the Era of Climate Change'. Presented at Ninth Essex Conference in Critical Political Theory. University of Essex (UK), 18 June 2010.

Bretherton, I. 1992. 'The Origins of Attachment Theory: John Bowlby and Mary Ainsworth', Developmental Psychology 28(5): 759-75.

Buchanan, J. M. and Tullock, G. 1962. The Calculus of Consent. Ann Arbor, MI: University of Michigan Press.

Buck-Morss, S. 2000. Dreamworld and Catastrophe: The Passing of Mass Utopia in East and West. Cambridge, MA: MIT Press.

Callahan, D. 1971. 'What Obligations do we Have to Future Generations?', The American Ecclesiastical Review 164(4): 265-8.

de-Shalit, A. 2000. 'Is Liberalism Environment-Friendly?', in de-Shalit (ed.), The Environment Between Theory and Practice. Oxford: Oxford University Press, 63-92.

Edelstein, M. R. 2004. Contaminated Communities: Coping with Residential Toxic Exposure. Boulder, CO: Westview Books.

Engster, D. 2006. 'Care Ethics and Animal Welfare', Journal of Social Philosophy 37(4): 521-36.

Engster, D. 2007. The Heart of Justice: Care Ethics and Political Theory. Oxford: Oxford University Press.

Farrell, K. N. 2010. Making Good Decisions Well: A Theory of Collective Ecological Management. Aachen: Shaker Verlag.

Fine, B. 2003. Social Capital versus Social Theory: Political Economy and Social Science at the Turn of the Millennium. London: Routledge.

Fraser, I. 1998. Hegel and Marx: The Concept of Need. Edinburgh: University of Edinburgh Press.

Gardiner, S. M. 2006. 'A Perfect Moral Storm: Climate Change, Intergenerational Ethics and the Problem of Moral Corruption', Environmental Values 15: 397-413.

Gheaus, A. 2010. 'The Heart of Justice: Care Ethics and Political Theory, by Daniel Engster', European Journal of Philosophy 18(4): 619-23.

Goodin, R. 1985. Protecting the Vulnerable: A Re-Analysis of Our Social Responsibilities. Chicago: Chicago of University Press.

Groves, C. 2009. 'Future Ethics: Risk, Care and Non-Reciprocal Responsibility', Journal of Global Ethics 5(1): 17-31.

Habermas, J. 1998. 'A Genealogical Analysis of the Cognitive Content of Morality', in Habermas, The Inclusion of the Other. Cambridge, MA: MIT Press, 3-46.

Harvey, D. 2003. The New Imperialism. Oxford: Oxford University Press.

Hoagland, S. L. 1990. 'Some Concerns about Nel Noddings' Caring', Hypatia 5(1): 109-14. 
Jaeggi, R. 2001. 'Solidarity and Indifference', in R. ter Meulen et al. (eds), Solidarity in Health and Social Care in Europe. Dordrecht: Kluwer, 287-308.

Kittay, E. F., et al. 2005. 'Dependency, Difference and the Global Ethic of LongTerm Care', The Journal of Political Philosophy 13(4): 443-69.

Macintyre, A. 1981. After Virtue: A Study in Moral Theory. London: Duckworth.

MacLean, D. 1983. 'A Moral Requirement for Energy Policies', in D. MacLean and P. Brown (eds), Energy and the Future. Totowa, NJ: Rowman and Allanheld, 180-97.

Marris, P. 1986. Loss and Change. London: Routledge \& Kegan Paul.

Marris, P. 1996. The Politics of Uncertainty: Attachment in Private and Public Life. London; New York: Routledge.

Mascarelli, A. L. 2010. 'A Bright Future for the Montreal Protocol', Environmental Science \& Technology 44(5): 1518-20.

Meyer, L. H. 2005. Historische Gerechtigkeit. Berlin: Walter de Gruyter.

Michel, D. 2009. 'Foxes, Hedgehogs, and Greenhouse Governance: Knowledge, Uncertainty, and International Policy-Making in a Warming World', Applied Energy 86(2): 258-64.

Morgan, P. 2010. 'Towards a Developmental Theory of Place Attachment', Journal of Environmental Psychology 30(1): 11-22.

Nowotny, H. 2003. 'Democratising Expertise and Socially Robust Knowledge', Science and Public Policy 30: 151-6.

O'Connor, M. 1994. 'On the Misadventures of Capitalist Nature', in M. O'Connor (ed.), Is Capitalism Sustainable? Political Economy and the Politics of Ideology. New York: Guilford Press, 125-51.

O’Neill, J. 1993. Ecology, Policy and Politics. London: Routledge.

O’Neill, J., et al. 2008. Environmental Values. Abingdon: Routledge.

Parfit, D. 1986. Reasons and Persons. Oxford: Oxford University Press.

Pellizzoni, L. 2004. 'Responsibility and Environmental Governance', Environmental Politics 13(3): 541-65.

Ravetz, J. 2004. 'The Post-Normal Science of Precaution', Futures 36(3): 347-57.

Rawls, J. 1972. A Theory of Justice. Oxford: Clarendon Press.

Raz, J. 1986. The Morality of Freedom. Oxford: Clarendon Press.

Robinson, F. 1999. Globalizing Care: Ethics, Feminist Theory, and International Relations. Oxford: Westview Press.

Rothstein, H. et al. 2006. 'A Theory of Risk Colonization: The Spiralling Regulatory Logics of Societal and Institutional Risk', Economy and Society 35(1): 91-112.

Smart, J. J. C. and Williams, B. 1973. Utilitarianism: For and Against. Cambridge: Cambridge University Press.

Stern, D. N. 1985. The Interpersonal World of the Infant: A View from Psychoanalysis and Developmental Psychology. New York: Basic Books. 
Stern, D. N. et al. 1998. The Birth of a Mother: How Motherhood Changes You Forever. London: Bloomsbury.

Thompson, A. 2006. 'Management Under Anarchy: The International Politics of Climate Change', Climatic Change 78(1): 7-29.

Tronto, J. C. 1993. Moral Boundaries: A Political Argument for an Ethic of Care. New York: Routledge.

van Hooft, S. 1995. Caring: An Essay in the Philosophy of Ethics. Colorado: University Press of Colorado.

Wallendorf, M. and Arnould, E. J. 1988. "My Favourite Things": A CrossCultural Inquiry into Object Attachment, Possessiveness, and Social Linkage', Journal of Consumer Research 14: 531-47.

Wynne, B. 1992. 'Uncertainty and Environmental Learning-Reconceiving Science and Policy in the Preventive Paradigm', Global Environmental Change-Human and Policy Dimensions 2(2): 111-27.

Young, R. M. 1989. 'Transitional Phenomena: Production and Consumption', in B. Richards (ed.), Crises of the Self: Further Essays on Psychoanalysis and Politics. London: Free Association Books, 57-72. 